Jurnal Maenpo: Jurnal Pendidikan Jasmani kesehatan dan Rekreasi

Volume 11 Nomor 1 Tahun 2021

https://jurnal.unsur.ac.id/maenpo

This Work Is Licensed Under A Creative Commons Attribution-

Sharealike 4.0 International License @) (1) (-)

Original Article

\title{
Effect of Parachute Running Training on 100 Meter Sprint Running Speed
}

\author{
Suharti ${ }^{1}$, Harwanto ${ }^{2}$, Ismawandi BP ${ }^{3}$ \\ ${ }^{123}$ Pendidikan Jasmani,Universitas PGRI Adibuana Surabaya, Indonesia \\ suharti@unipasby.ac.id', harwanto@unipasby.ac.id ${ }^{2}$ IsmwandiBP@unipasby.ac.id ${ }^{3}$
}

\begin{abstract}
ABSTRAK
Penelitian ini bertujuan untuk mengetahui seberapa besar pengaruh latihan lari parachute running terhadap kecepatan lari sprint 100 meter siswa kelas X MA Darul Ulum Waru Sidoarjo. Penelitian ini adalah penelitian kuantitatif dengan metode eksperimen. Desain penelitian yang digunakan adalah One Group Pretest and Posttest Design, yaitu eksperimen yang dilaksanakan pada satu kelompok tanpa kelompok pembanding. Sedangkan sampel dalam penelitian ini berjumlah 20 siswa di MA Darul Ulum Waru Sidoarjo. Berdasarkan hasil penelitian, diketahui bahwa nilai pretest minimal 15.28, maksimal 21.09 , sedangkan nilai posttest minimal 15 maksimal 16.72, sedangkan nilai sig. (2-tailed) pada kelompok eksperimen yaitu sebesar 028, sehingga nilai sig (2-tailed) $<0.05$, maka dapat dikatakan $\mathrm{H}_{\circ}$ ditolak dan $\mathrm{H}_{\mathrm{a}}$ diterima, dapat disimpulkan bahwa ada pengaruh pada latihan lari dengan menggunakana Parachute Running terhadap kecepatan lari sprint 100 meter (Siswa Kelas $\mathrm{X}$ MA Darul Ulum Waru Sidoarjo). Dari hasil penelitian ini diharapkan latihan lari dengan menggunakan Parachute Running dapat menjadi rujukan sebagai variasi latihan lari sprint agar tidak monoton.
\end{abstract}

Kata Kunci: parachute running, lari sprint 100 meter.

\section{ABSTRACT}

This study aims to determine how much influence the parachute running exercise has on the 100-meter sprint running speed of class X MA Darul Ulum Waru Sidoarjo. This research is quantitative research with experimental method. The research design used was One Group Pretest and Posttest Design, namely experiments carried out in one group without a comparison group. While the sample in this study found 20 students at MA Darul Ulum Waru Sidoarjo. Results Based on the research, it is known that the minimum pretest value is 15.28, the maximum is 21.09, while the posttest value is at least 15 and the maximum is 16.72, while the sig. (2-tailed) in the experimental group is 028, so the value of sig (2-tailed) $<0.05$, it can be said that Ho is rejected and accepted, it can be said that there is an effect on running training using Parachute Running on sprint running speed 100 meters (Students of Class X MA Darul Ulum Waru Sidoarjo). From the results of this study, it is hoped that running exercises using Parachute Running can be a reference as a variation of sprint running exercises so that they are not monotonous.

Keywords: parachute running, 100 meter sprint. 
Received: 03-06-2021; Accepted: 14-06-2021; Published: 20-06-2021

\section{PENDAHULUAN}

Pendidikan olahraga yang dalam hal ini adalah pendidikan jasmaani adalah mata pelajaran yang ada disekolah yang menjadi media penggerak perkembangan fisik motorik, kognitif, sportifitas, penerapan gaya hidup sehat dan proses terbentuknya karakter (spiritual, sosioemosional, dan mental) untuk mewujudkan tercapainya tujuan sistem pendidiikan nasional. Siswa sekolah pada umumnya senang saat pembelajaran di luar kelas seperti olahraga, karena olahraga di sekolah adalah kesempatan bermain dengan teman. Sehingga siswa kurang bersemangat pada saat olahraga serta masih banyaknya pelajar yang bermalas malasan, tidak aktif bergerak, dan bersenda gurau dengan temannya. Salah satunya ketika pembelajaran lari jarak pendek, siswa kurang serius dan kurang fokus terhadap materi dan praktiknya terutama pada saat melakukan tahapan lari sprint mulai dari start sampai finish. Sehingga perlu adanya variasi latihan lari jarak pendek dengan memakai parachute running, agar siswa lebih tertarik dalam mengikuti pembelajaran.

Latihan sprint training menggunakan parasut running merupakan metode latihan yang dapat digunakan untuk meningkatkan kecepatan lari 100 meter. Namun demikian, dari hasil penelitian dapat diketahui bahwa latihan sprint training menggunakan parasut running memiliki pengaruh yang lebih baik daripada sprint training tanpa menggunakan parasut running dalam meningkatkan kecepatan lari 100 meter. Dalam penelitian ini didapatkan bahwa terjadi peningkatan kecepatan lari 100 meter Siswa Kelas X MA Darul Ulum Waru Sidoarjo. Hal tersebut dapat menjadi dasar pemikiran dan acuan bagi para pembina dan pelatih tentang metode latihan dengan menggunakan parasut running untuk meningkatkan kecepatan lari 100 meter pada anak didiknya. Sebagian besar para pelatih menerapkan model latihan ketika menjadi atlet tanpa melakukan inovasi model latihan, termasuk pelatih atletik. Kejadian ini menyatakan bahwa kecanggihan teknologi dan sport science belum diaplikasikan 
dengan baik. Cina merupakan negara dengan tingkat ilmu keolahragaan dan kemajuan teknologinya mempunyai peran yang sangat besar terhadap peningkatan prestasi atletnya. Sistematika latihan yang disusun dengan baik sesuai kaidah ilmu keolahragaan, dengan memperhatikan perkembangan fisik, adaptasi fisiologis, kondisi fisik, akan menghasilkan atlet-atlet yang berpotensi tinggi dalam upaya meraih prestasi yang maksimal. Karena masih banyaknya pelatih yang menggunakan metode latihan yang konvesional perlu adanya inovasi model latihan dengan tujuan untuk mengurangi rasa bosan pada atlet dan inovasi latihan tersebut sebagai upaya untuk meningkatkan performa. Sprint running dengan menggunakan Parachute running adalah salah satu metode latihan yang dipilih untuk meningkatkan kecepatan lari yang dilakukan secara berulang-ulang dalam intensitas dan pembebanan maksimal dengan menggunakan parasut. Latihan ini dapat menghasilkan pengaruh yang sangat besar dalam meningkatkan kecepatan lari seratus meter. Parachute running adalah sebuah alat yang dipakai untuk meningkatkan kecepatan lari karena adanya beban udara yang menekan dari depan sehingga akan memberikan daya tekanan pada saat berlari dan apabila latihan ini dilakukan secara tepat dan dilakukan secara berulang-ulang maka akan meningkatkan kecepaatan lari dan daya ledak otot tungkai pada saat aksselerasi.

Parachute running ini dirancang untuk pelari saat berlari dengan kecepatan maksimal sebagai gaya hambat saat parachute terbuka sehingga dapat membantu pelari membangun kecepatan. Parachute running ini dibuat dengan bahan kain yang tidak mudah sobek serta ada tali yang melekat dan pengait untuk dihubungkan atau diletakkan ketubuh pelari saat berlari. Dan ketika digunakan untuk berlari, parachute akan terbuka dan menciptakan gaya hambat untuk pelari agar dapat meningkatkan dan membangun kecepatan terbaik pelari. Salah satu kelebihan dari alat ini adalah alat ini bisa menciptakan gaya hambatan yang membuat pelari harus bekerja lebih keras untuk melawan hambatan ini agar lari menjadi cepat. Ini akan membantu pelari meningkatkan kecepatan \& kekuatannya karena otot-otot bekerja keras untuk melawan hambatan dengan cara berlari sekuat mungkin dalam waktu singkat. 
Cara menggunakan Parachute Running dengan mengikatkan ujung tali parachute dengan pinggang pelari, jadi pada saat berlari parasut akan membuka sehingga dapat memberikan hambatan pada saat berlari atau dapat disebut sebagai beban pada saat pelari berlari. Namun biasanya kelemahan saat melakukan latihan lari cepat tidak menggunakan beban atau tahanan sebagai rintangan, jadi tidak ada tantangan untuk meningkatkan performa kecepatan dalam berlari.

Maka dari uraian diatas, peneliti ingin membuat jenis latihan lari sprint agar tidak monoton dan siswa lebih semangat serta fokus dengan adanya rintangan baru berupa parachute running sebagai tahanan saat berlari karena adanya tantangan dalam latihan tidak lagi (menggunakan beban tubuh sendiri) tanpa alat beban sebagai rintangan. Dengan adanya latihan antara tidak menggunakan beban parachute run dan menggunakan parachute run ini dapat menimbulkan perbedaan waktu kecepatan dan jarak pelari menjadi meningkat. Karena dengan adanya beban parachute run sebagai tahanan tarikan, pelari diharap dapat mempertahankan bahkan meningkatkan performa kecepatan berlari nya karena adanya suatu beban atau rintangan yang harus dilewati diharap kecepatan maksimal dan waktu serta jarak dalam berlari meningkat.

\section{METODE}

Metode eksperimen adalah metode yang digunakan dalam penelitian ini, dengan memakai rancangan penelitian pre posttest design. Desain penelitian menggunakan One Group Pre Posttest Design.

$$
\mathbf{R}^{1} \times \mathbf{R}^{2}
$$

Gambar. Desain Penelitian

Sumber : (Yuliardi Ricky, 2017)

Keterangan:

$$
\begin{array}{cl}
\mathbf{R}^{\mathbf{1}} & : \text { Sebelum diberikan latihan } \\
\mathrm{X} & : \text { Latihan } \\
\mathbf{R}^{2} & : \text { Sesudah diberikan latihan }
\end{array}
$$




\section{HASIL DAN PEMBAHASAN}

\section{Hasil Penelitian}

Bedasarkan hasil kajian dilapangan yang didasarkan pada judul penelitian yakni Pengaruh Latihan Lari Parachute Running terhadap kecepatan Lari Sprint seratus meter (Siswa Kelas X MA Darul Ulum Waru Sidoarjo) maka data dilapangan dapat dilihat pada tabel.

Analisis diskriptif

\section{Tabel1}

Descriptive Statistics

\begin{tabular}{lrrrrr}
\hline & & & & & \multicolumn{2}{c}{$\begin{array}{c}\text { Std. } \\
\text { Deviati } \\
\text { on }\end{array}$} \\
\hline Pre_test & & Minimum & Maximum & Mean & (15.28 \\
Post_test & 20 & 15.21 .09 & 17.6470 & 1.69114 \\
Valid N (listwise) & 20 & 15.00 & 16.72 & 16.0315 & .48347 \\
\hline
\end{tabular}

Dari hasil data diatas terdapat rata rata pretest 17.6470 sedangkan posttest mendapatkan hasil 16.0315. Hal ini membuktikan bahwa latihan lari dengan parachute running memberikan dampak peningkatan kecepatan lari yang signifikan.

Uji Normalitas Data

Tabel 2

\begin{tabular}{|c|c|c|c|c|c|c|}
\hline \multicolumn{7}{|c|}{ Test of Normality } \\
\hline & \multicolumn{3}{|c|}{ Kolmogorov-Smirnov $^{\mathrm{a}}$} & \multicolumn{3}{|c|}{ Shapiro-Wilk } \\
\hline & Statistic & df & Sig. & Statistic & df & $\begin{array}{c}\text { Sig } \\
\text {. }\end{array}$ \\
\hline Pre_test & .142 & 20 & $.200^{*}$ & .939 & 20 & $\begin{array}{r}.23 \\
0\end{array}$ \\
\hline Post_test & .134 & 20 & $.200^{*}$ & .952 & 20 & .39 \\
\hline
\end{tabular}

*. This is a lower bound of the true significance.

a. Lilliefors Significance Correction 
Berdasarkan data pada tabel di atas, maka dapat disimpulkan bahwa hasil uji normalitas pada data penelitian diperoleh nilai signifikan semua lebih besar dari $p$ value 0.05 maka dinyatakan data berdisitribusi normal.

Uji Homogenitas

Tabel 3

Test of Homogenity of Variance

\begin{tabular}{lccccr}
\hline & Levene Statistic & df1 & df2 & Sig. \\
\hline Pre_test & .000 & & 1 & 18 & .999 \\
Post_test & .496 & & 1 & 18 & .490 \\
\hline
\end{tabular}

Berdasarkan data pada tabel di atas, maka dapat disimpulkan bahwa hasil uji homogenitas diperoleh nilai signifikan semua lebih besar dari $p$-value 0.05 , maka data berdisitribusi homogen. Hal ini menunjukan syarat untuk uji t bisa di lanjutkan.

Hasil uji paired sampel t test (Uji T)

Tabel 4

Paired Sample Test

\begin{tabular}{|c|c|c|c|c|c|c|c|c|c|}
\hline & \multicolumn{5}{|c|}{ Paired Differences } & \multirow[b]{4}{*}{$\mathrm{t}$} & \multirow[b]{4}{*}{ df } & \multirow{4}{*}{$\begin{array}{l}\text { Sig. (2- } \\
\text { tailed) }\end{array}$} \\
\hline & & \multirow{3}{*}{$\begin{array}{c}\text { Mea } \\
\mathrm{n}\end{array}$} & \multirow{3}{*}{$\begin{array}{l}\text { Std. } \\
\text { Deviati } \\
\text { on }\end{array}$} & \multirow{3}{*}{$\begin{array}{l}\text { Std. } \\
\text { Error } \\
\text { Mean }\end{array}$} & \multirow{2}{*}{\multicolumn{2}{|c|}{$\begin{array}{c}95 \% \text { Confidence } \\
\text { Interval of the } \\
\text { Difference }\end{array}$}} & & & \\
\hline & & & & & & & & & \\
\hline & & & & & Lower & Upper & & & \\
\hline $\begin{array}{l}\text { Pai } \\
\text { r } 1\end{array}$ & $\begin{array}{l}\text { Pre_test } \\
\text { Post_test }\end{array}$ & $\begin{array}{r}1.61 \\
550\end{array}$ & 1.38460 & .30961 & .96749 & 2.26351 & $\begin{array}{r}5.21 \\
8\end{array}$ & 19 & .000 \\
\hline
\end{tabular}

Data yang diperoleh dari Hasil Uji T, menyatakan bahwa hasil pretest dan posttest terdapat adanya perbedaan atau terdapat pengaruh yang sangat berarti diantara data masing-masing variabel, dapat dikatakan bahwa $\mathrm{H}_{\mathrm{o}}$ ditolak dan $\mathrm{H}_{\mathrm{a}}$ diterima sehingga dapat disimpulkan ada pengaruh latihan Lari Parachute Running terhadap Kecepatan Lari Sprint 100 meter. 


\section{Pembahasan}

Berdasarkan dari hasil analisis diskriptif penelitian dan pengolahan data yang sudah dilakukan di atas terdapat pengaruh yang signifikan terhadap hasil pretest dan posttest latihan lari dengan menggunakan Parachute Running pada kecepatan lari sprint seratus meter. Hasil analisis ini membuktikan bahwa rerata latihan lari dengan menggunakan Parachute Running pada subjek penelitian sebelum diberi latihan adalah sebesar 10,3941 dan setelah diberi latihan adalah 10,2771. Meskipun demikian ketika melakukan lari dengan dengan menggunakan parasut, dilakukan dengan posisi yang benar di belakang pusat tubuh dari gravitasi yang penyebabnya adalah udara. (Herrington et al., 2019). Dianjurkan ketika latihan memakai parachute running dapat meningkatkan kekuatan daya pinggul dan lutut otot sendi (Martinopoulou et al., 2011). Latihan ini dapat meningkatkan daya dorong pada saat melakukan lari (Herrington et al., 2019). Tabachnik menemukan metode latihan dengan parasut yang menurutnya sangat bagus sebagai upaya memperbaiki beberapa bidang seperti fase kecepatan yang terdiri dari start, percepatan, sampai pada kecepatan maksimal dan juga memeiliki fungsi untuk membantu melewati hambatan kecepatan. Cara ini dapat membantu mengoptimalkan ketahanan dengan memaksimalkan kecepatan berlari tanpa merubah teknik. Hasil tersebut dapat dilihat dari hasil data berikut ini: Untuk Hasil Analisis Deskriptif dari hasil data terdapat rata-rata pretest 17.6470 sedangkan posttest 16.0315 setelah diberikan perlakuan. Latihan lari dengan parasut dapat menambah derajat kecepatan lari sprint seratus meter. Pernyataan ini dibuktikan dengan hasil nyata bahwa untuk meningkatkan daya pada otot pinggul dan lutut sendi yang berkelanjutan dapat meningkatkan langkah panjang dan dorongan, sebagai syarat perbaikan kecepatan dalam fase akselerasi.

"The SL increase confirms the study assumption that resisted sprint training with parachute modifies sprint stride kinematics" (Rebolledo \& Emlet, 2015) menyatakan bahwa latihan lari dengan menggunakan Parachute Running meningkatkan kecepatan lari sprint seratus meter karena panjang langkahnya mengalami peningkatan, namun tidak nampak adanya perubahan peningkatan yang 
berarti dalam hal frekuensi langkah. (Martinopoulou et al., 2011) latihan lari dengan menggunakan Parachute Running adalah metode latihan spesifik yang mempelajari kecepatan dalam berlari dan kecepatan dalam bergerak. Sebab itu, apabila diterapkan hasil penyesuaian pelatihannya lebih meningkat terhadap kecepatan, daripada metode latihan yang lain.

Dari data yang diperoleh hasil Uji T menunjukkan bahwa data pretest dan posttest terdapat adanya perbedaan atau pengaruh yang sangat signifikan, antara data pada beberapa variabel. Dapat dikatakan bahwa $\mathrm{H}_{\mathrm{o}}$ ditolak dan $\mathrm{H}_{\mathrm{a}}$ diterima, sehingga dapat disimpulkan bahwa ada pengaruh latihan Lari Parachute Running terhadap Kecepatan Lari Sprint seratus meter. Melakukan latihan lari dengan maksimal dengan bermacam-macam jarak sangatlah penting bagi banyak orang khususnya olahragawan. Sebab itu, kondisi professional dan kekuatan seseorang mampu mendapatkan perhatian besar pada latihan lari sprint seratus meter, latihan secara berurutan untuk mengoptimalkan kinerja kecepatan lari sprint seratus meter. Menurut (Gleadhill et al., 2020). "Bagi pelatih lintasan sudah mempercayai dan didukung oleh beberapa penelitian tentang konsep yang kinerjanya singkat terhadap kecepatan laris sprint seratus meter (contohnya, $10 \mathrm{~m}$ ) dan lari sprint yang memungkinkan pencapaian maksimal atau hampir maksimal kecepatan (contohnya, $50 \mathrm{~m}$ )". hal ini dapat dikatakan bahwa seorang atlet dapat memiliki prestasi dalam lari cepat jarak pendek namun tidak dalam kecepatan maksimal, atau sebaliknya. Oleh sebab itu, kita harus memperhatikan berbagai kwaalitas lari cepat jarak pendek dalam olahraga untuk memilih jenis latihan yang harus diberikan kepada masing-masing (Young et al., 2001). Banyak hal yang memungkinkan pengembangan kecepatan lari Sprint 100 meter yang membutuhkan akselerasi dan kecepatan berlari maksimal (Young et al., 2001).

\section{SIMPULAN}

Dari hasil data penelitian yang telah dilaksanakan maka dapat ditarik kesimpulan bahwa ada pengaruh latihan Lari Parachute Running terhadap kecepatan Lari Sprint 100 meter. Diharapkan untuk penelitian selanjutnya dapat memilih metode latihan 
120 | Suharti 1*, Harwanto2, Ismawandi BP ${ }^{3}$

The Effect of Parachute Running Training on 100 Meter Sprint Running Speed

parachute running terhadap variabel lain sehingga latihan parachute running memiliki dampak atau pengaruh terhadap variabel variabel yang dipilih.

\section{DAFTAR PUSTAKA}

Gleadhill, S., Kai, T., \& Nagahara, R. (2020). Resist-and-release sprint running using parachute towing causes detrimental changes to performance, kinematics, and kinetics. Journal of Physical Education and Sport. https://doi.org/10.7752/jpes.2020.06461

Herrington, S. M., Daniel, J. C., Sackett, T. K., Fields, T. D., \& Yakimenko, O. A. (2019). Experimental investigation into the effects of geometry on the glide performance of cruciform parachutes. AIAA Aviation 2019 Forum. https://doi.org/10.2514/6.2019-3148

Martinopoulou, K., Argeitaki, P., Paradisis, G., Katsikas, C., \& Smirniotou, a. (2011). The Effects of Resisted Training Using Parachuteon Sprint Performance. Biology of Exercise.

Paulson, S., \& Braun, W. A. (2011). The influence of parachute-resisted sprinting on running mechanics in collegiate track athletes. Journal of Strength and Conditioning Research. https://doi.org/10.1519/JSC.0b013e3181dba3f5

Rebolledo, A. P., \& Emlet, R. B. (2015). The parachute function of the hull in eggs of Mopalia kennerleyi (Chitonida: Mopaliidae), and swimming of its larvae through ontogeny. Invertebrate Biology. https://doi.org/10.1111/ivb.12076

Young, W., Benton, D., Duthie, G., \& Pryor, J. (2001). Resistance Training for Short Sprints and Maximum-speed Sprints. Strength and Conditioning Journal. https://doi.org/10.1519/00126548-200104000-00001

Yuliardi Ricky, Z. N. (2017). Statistik Penelitian Plus Tutorial SPSS. Yogyakarta Innosain.

Laksana, G. S., \& Sumirat, D. (2020). Kontribusi Kebugaran Jasmani Dan Tingkat Intelegensi Dengan Tingkat Penguasaan Keterampilan Gerak Seni Padungdung Dalam Olahraga Bela Diri Pencak Silat. Jurnal Maenpo: Jurnal Pendidikan Jasmani Kesehatan Dan Rekreasi. https://doi.org/10.35194/jm.v10i2.1151

Rivan Syukur, M., \& Kastrena, E. (2019). Kontribusi Daya Ledak Otot Lengan Dan Daya Ledak Otot Tungkai Terhadap Hasil Smash. MAENPO. https://doi.org/10.35194/jm.v9i1.905

Zakky Mubarok, M. (2020). Pengaruh Metode Latihan Interval Dan Kemampuan Agility Terhadap Peningkatan Keterampilan Dribbling Permainan Sepak Bola. MAENPO. https://doi.org/10.35194/jm.v8i2.924 